\title{
Monoclonal antibodies targeting non-small cell lung cancer stem-like cells by multipotent cancer stem cell monoclonal antibody library
}

\author{
KAIYUE CAO, YUNZHI PAN, LONG YU, XIONG SHU, JING YANG, \\ LINXIN SUN, LICHAO SUN, ZHIHUA YANG and YULIANG RAN \\ National Cancer Center/Cancer Hospital, Chinese Academy of Medical Sciences \\ and Peking Union Medical College, Beijing 100021, P.R. China
}

Received October 19, 2016; Accepted December 14, 2016

DOI: $10.3892 /$ ijo.2016.3818

\begin{abstract}
Cancer stem cells (CSCs) are a rare subset of cancer cells that play a significant role in cancer initiation, spreading, and recurrence. In this study, a subpopulation of lung cancer stem-like cells (LCSLCs) was identified from non-small cell lung carcinoma cell lines, SPCA-1 and A549, using serum-free suspension sphere-forming culture method. A monoclonal antibody library was constructed using immunized BLAB/c mice with the multipotent CSC cell line T3A-A3. Flow cytometry analysis showed that $33 \mathrm{mAbs}$ targeted antigens can be enriched in sphere cells compared with the parental cells of SPCA-1 and A549 cell lines. Then, we performed functional antibody screening including sphere-forming inhibiting and invasion inhibiting assay. The results showed that two antibodies, 12C7 and 9B8, notably suppressed the self-renewal and invasion of LCSLCs. Fluorescence-activated cell sorting (FACs) found that the positive cells recognized by mAbs, $12 \mathrm{C} 7$ or 9B8, displayed features of LCSLCs. Interestingly, we found that these two antibodies recognized different subsets of cells and their combination effect was superior to the individual effect both in vitro and in vivo. Tissue microarrays were applied to detect the expression of the antigens targeted by these two antibodies. The positive expression of 12C7 and 9B8 targeted antigen was 84.4 and $82.5 \%$, respectively, which was significantly higher than that in the non-tumor lung tissues. In conclusion, we screened two potential therapeutic antibodies that target different subsets of LCSLCs.
\end{abstract}

\footnotetext{
Correspondence to: Professor Yuliang Ran, National Cancer Center/ Cancer Hospital, Chinese Academy of Medical Sciences and Peking Union Medical College, Beijing 100021, P.R. China

E-mail: ran_yuliang@126.com
}

Key words: lung cancer stem-like cells, monoclonal antibody, sphere, 12C7, 9B8, antibody effect

\section{Introduction}

Lung cancer is the most common cause of cancer-related deaths worldwide $(1,2)$. The overall prognosis is poor with low 5-year survival due to tumor metastasis and relapse. The cancer stem cells (CSCs) have been proposed in many types of malignancies in both leukemia and solid tumors (3-6). Accumulating evidence supports that CSCs could be responsible for tumor initiation, progression, and distant metastasis (7-9). Due to the vital role of CSCs in cancer prognosis, targeted therapies that can eradicate these cells may eventually lead to cancer cures (10-12). Although many cancer stem markers have been identified in solid tumors including melanoma (13), breast (14), pancreatic (15) and lung cancer (16), few of them can be used as therapeutic targets owing to the lack of specificity and functional relevance.

Monoclonal antibody-based treatment of cancer has been established as one of the most successful therapeutic strategies for treating patients with malignant tumors in the last two decades (17-19). Hybridoma technologies, developed by Köhler and Milstein, for the first time, allowed the generation of monoclonal antibodies with high specificity (20). Numerous mAbs such as rituximab, bevacizumab, trastuzumab and emtansine, approved by the USFDA for the treatment of both hematologic and solid human cancers, have significantly improved the clinical outcomes of cancer patients (21). Antibodies can lead to direct cell killing through receptor blockade or agonist activity and induction of apoptosis. Several monoclonal antibodies targeting CSCs have been proposed (22-24). However, therapeutic antibodies specific for lung cancer stem-like cells (LCSLCs), have not yet been reported. Thus, we present here a novel screening approach to identify functional antibodies targeting LCSLCs.

In a previous study (25), we obtained the multipotent CSC cell line T3A-A3, derived from a human primary liver cancer tissue, which possesses high tumorigenic and metastatic potential and expresses various stem cell-related markers including Sox2, Lin28, Nanog, c-Myc and Klf4. Interestingly, T3A-A3 cells can differentiate into corresponding tumor cells 
when treated with the tumor cell/tissue-derived conditioned culture medium. In this study, we constructed a multipotent CSC monoclonal antibody library containing 2976 mAbs by immunizing the BLAB/c mice with T3A-A3 cells. As a result of assessing the antibody concentration by ELISA and fixed cell immunofluorescence, 66 monoclonal antibodies that could recognize lung cancer cells were obtained. Then, we enriched the LCSLCs using serum-free suspension culture method and screened the constructed monoclonal antibody library with the objective of identifying the functional antibodies targeted to LCSLCs. Two antibodies were selected from the library that could significantly inhibit the self-renewal and invasion of LCSLCs. Further study found that these two antibodies recognized two distinct LCSLCs and their combination effect were notably better than the individual effect. Thus, our results suggested that this combination might become a potential novel therapy for lung cancer.

\section{Materials and methods}

Monoclonal antibody library construction. A library of monoclonal antibodies was constructed according to the standard protocol described previously (26). Briefly, T3A-A3 cells were harvested in the logarithmic phase of growth and washed twice with phosphate-buffered saline (PBS). A part of the cells was suspended in PBS at $1 \times 10^{7} / \mathrm{ml}$ and intraperitoneally injected $0.5 \mathrm{ml}$ into six $\mathrm{BALB} / \mathrm{C}$ mice (BFK Bioscience, Beijing, China). The rest of the cells were fixed with $4 \%$ paraformaldehyde for $30 \mathrm{~min}$ and washed twice with PBS. Then the cells were suspended in PBS at $1 \times 10^{7} / \mathrm{ml}$ and subcutaneously injected $0.5 \mathrm{ml}$ into the above-mentioned mice. Two weeks later, the same amount of fixed cells was subcutaneously injected into the mice for booster immunization per week. Following eighth booster doses, the serum antibody concentration of the mice was assessed by ELISA. Subsequently, the splenic cells of the mouse with the highest serum titer was used to fuse with SP $2 / 0$ cells, which were maintained in HAT medium supplemented with $2.5 \%$ methylcellulose (Sigma, St. Louis, MO, USA) in an atmosphere of $5 \% \mathrm{CO}_{2}$ at $37^{\circ} \mathrm{C}$. After culturing for 8-10 days, the monoclonal library containing 2976 clones was established.

The hybridoma cells were maintained in the complete DMEM growth medium (Invitrogen, Carlsbad, CA, USA). The hybridoma supernatant collection, antibody production, and purification were performed using standard protocols. The isotype of the antibody was determined by commercial isotyping kit (SouthernBiotech, Birmingham, AL, USA).

Cell culture. Human non-small cell lung carcinoma cell lines SPCA-1 and A549 were purchased from Chinese Academy of Sciences Cell Bank (Shanghai, China). Cells were cultured in RPMI-1640 media containing 10\% fetal bovine serum (Gibco, Grand Island, NY, USA), $1 \%$ glutamine, and $1 \%$ penicillinstreptomycin sulfate (Invitrogen). All the cell lines were grown at $37^{\circ} \mathrm{C}$ in $5 \% \mathrm{CO}_{2}$ incubator. T3A-A3 cell line was a gift from Professor J. Lou of Institute of Clinical Medical Sciences, China-Japan Friendship Hospital. T3A-A3 cell line was maintained in DMEM-F12 supplemented with $1 \%$ FBS, B27 (1:50; Invitrogen), $20 \mathrm{ng} / \mathrm{ml}$ human epidermal growth factor (EGF; Invitrogen), $10 \mathrm{ng} / \mathrm{ml}$ basic fibroblast growth factor
(bFGF; Invitrogen), $2 \mathrm{mg} / \mathrm{ml}$ heparin (Sigma), $1 \%$ glutamine, and $1 \%$ penicillin-streptomycin sulfate (Invitrogen), $5 \mathrm{mg} / \mathrm{ml}$ insulin (Sigma) and $0.5 \mathrm{mg} / \mathrm{ml}$ hydrocortisone (Sigma).

Sphere-forming culture and self-renewal assay. To obtain sphere cultures, cells were plated at a density of $3 \times 10^{4}$ cells/T75 ultra-low flask (Corning, NY, USA) containing $15 \mathrm{ml}$ serum-free medium (SFM) DMEM/F12, supplemented with B27, $20 \mathrm{ng} / \mathrm{ml} \mathrm{EGF,} 20 \mathrm{ng} / \mathrm{ml} \mathrm{bFGF,} 10 \mathrm{ng} / \mathrm{ml} \mathrm{LIF}$ (Invitrogen), $1 \%$ glutamine, and $1 \%$ penicillin-streptomycin sulfate. After being cultured for 7 days, the lung cancer spheres were collected, dissociated into single cell suspension by trypsin-EDTA solution and cultured to allow the regeneration of spheres. Third-generation spheres were used for all subsequent experiments.

To investigate the sphere formation and self-renewal capacity, the cells were plated in 24-well ultralow attachment plates (Corning) at a density of 500 cells/well in the SFM with $0.8 \%$ methylcellulose (Sigma). The cultures were incubated at $37^{\circ} \mathrm{C}$ in $5 \% \mathrm{CO}_{2}$. After 11 days, the spheroid colonies were counted under a microscope. The cloning efficiency was calculated as the percentage of the original number of seeded cells forming colonies of $>20$ cells.

Flow cytometry analysis and fluorescence-activated cell sorting (FACs). For antibody library screening, SPCA-1 or A549 cells $\left(1 \times 10^{6}\right)$ were incubated with the monoclonal antibody supernatants followed by Alexa 488 goat anti-mouse (IgG+IgM) (Jackson, NY, USA). In order to explore if mAbs $12 \mathrm{C} 7$ and 9B8 recognized the same cell group, we independently conjugated their purified antibodies to Alexa 488 (Santa Cruz, CA, USA) and allophycocyanin (APC) according to the manufacturer's instructions. Subsequently, the reaction was incubated with the cells in the same tube for flow cytometry analysis using an LSR II flow cytometer (BD Bioscience, CA, USA). For fluorescence-activated cell sorting (FACs), cells were labeled under sterilized conditions and sorted. The data were analyzed by FlowJo software version 5.7.1 (Tree star).

Transwell invasion assay. For invasion assay, $2 \times 10^{4}$ cells were plated in the top chamber of the Matrigel-coated membrane (24-well insert; pore size, $8 \mu \mathrm{m}$; Corning). Each upper chamber was precoated with Matrigel (BD Bioscience) according to the manufacturer's protocol before the invasion assay. Cells were plated in the medium without serum or growth factors, and the medium containing $10 \%$ FBS was used as a chemoattractant in the lower chamber. The cells were incubated for $24 \mathrm{~h}$, and those that did not invade through the pores were removed by a cotton swab. The cells on the lower surface of the membrane were fixed with methanol and stained with crystal violet. The number of cells invading through the membrane was counted under a light microscope (three random fields/well).

Tumorigenicity assay and antibody treatment of tumorbearing mice. For tumorigenicity assay, SPCA-1 or A549 cells were injected subcutaneously into the back of 4-week-old BALB/C-nude mice (BFK Bioscience) at a dose of $1 \times 10^{6}$, $1 \times 10^{5}, 1 \times 10^{4}$ and $5 \times 10^{3}$ cells, respectively. The tumor growth was monitored every 7 days after the inoculation. 
Table I. Primers for the real-time PCR analysis.

\begin{tabular}{lcl}
\hline Gene & Direction & \multicolumn{1}{c}{ Primer sequences (5'-3') } \\
\hline Sox2 & F & AACCAAGACGCTCATGAAGAAG \\
& R & CTGCGAGTAGGACATGCTGTAG \\
Oct4 & F & GACAACAATGAAAATCTTCAGGAGA \\
& R & TTCTGGCGCCGGTTACAGAACCA \\
Nanog & F & GTCCCAAAGGCAAACAACCC \\
& R & GCTGGGTGGAAGAGAACACA \\
GAPDH & F & TGCACCACCAACTGCTTAGC \\
& R & GGCATGGACTGTGGTCATGAG
\end{tabular}

For antibody treatment of the tumor-bearing mice, 4-week-old BALB/C-nude mice were randomly divided into nine groups of five animals each. The weights of mice in each treatment cohort were similar. SPCA-1 sphere cells $\left(5 \times 10^{5}\right)$ were injected subcutaneously into the armpit of the right forelimb of the mice. Treatment began 3 days after the injection of the tumor cells. The nine groups received intraperitoneal injections of i) PBS, ii) $40 \mathrm{mg} / \mathrm{kg}$ of mouse IgG for negative control, iii) $40 \mathrm{mg} / \mathrm{kg}$ of $\mathrm{mAb} 12 \mathrm{C} 7$ for high dose treatment, iv) $10 \mathrm{mg} / \mathrm{kg}$ of mAb $12 \mathrm{C} 7$ for medium dose treatment, v) $2.5 \mathrm{mg} / \mathrm{kg}$ of mAb $12 \mathrm{C} 7$ for low dose treatment, vi) $40 \mathrm{mg} / \mathrm{kg}$ of $\mathrm{mAb} 9 \mathrm{~B} 8$ for high dose treatment, vii) $10 \mathrm{mg} /$ $\mathrm{kg}$ of mAb 9B8 for medium dose treatment, viii) $2.5 \mathrm{mg}$ / $\mathrm{kg}$ of $\mathrm{mAb} 9 \mathrm{~B} 8$ for low dose treatment, ix) combination of $\mathrm{mAb} 12 \mathrm{C} 7$ and $9 \mathrm{~B} 8$ with $20 \mathrm{mg} / \mathrm{kg}$ of each. The respective dosages were administered twice a week for 4 weeks. The animals were sacrificed, and tumors were weighed 33 days after incubation.

All animal experiments were approved by The Animal Care and Use Committee of Cancer Hospital, Chinese Academy of Medical Science, and Peking Union Medical College (Beijing, China).

Real-time fluorescence quantitative polymerase chain reaction (RT-qPCR). Total RNA was extracted using Aurum ${ }^{\mathrm{TM}}$ total RNA mini kit (Bio-Rad, CA, USA) and reverse transcribed into cDNA using TaqMan reverse transcription reagents (Bio-Rad). RT-PCR was performed with SsoFast ${ }^{\mathrm{TM}}$ EvaGreen Supermix with Low ROX (Bio-Rad). The quantitative PCR reaction was carried out in a 7500 Fast Real-Time PCR system (Applied Biosystems, Foster City, CA, USA). The reaction conditions were as follows: $95^{\circ} \mathrm{C}$ for $30 \mathrm{sec}$ and 40 cycles at $95^{\circ} \mathrm{C}$ for $10 \mathrm{sec}$ and $60^{\circ} \mathrm{C}$ for $15 \mathrm{sec}$. The gene expression was quantified using the comparative $\mathrm{Ct}$ method. The primer sequences utilized are listed in Table I. GAPDH expression was used for normalization.

Western blot analysis. For western blot analysis, the whole proteins extract was prepared from lung cancer cell lines SPC-A1 and A549 by RIPA buffer (Beyotime, Beijing, China) supplemented with a cocktail of protease inhibitors (Sigma). The proteins were resolved by $12 \%$ SDS-PAGE, transferred to PVDF membranes, and then probed with primary antibodies,
$\mathrm{mAb} 12 \mathrm{C} 7(10 \mu \mathrm{g} / \mathrm{ml})$ and 9B8 $(10 \mu \mathrm{g} / \mathrm{ml})$. The immunoreaction was visualized by super ECL detection reagent (Life Technologies, Carlsbad, CA, USA) following incubation with HRP-conjugated secondary antibodies.

Immunohistochemistry with tissue microarray. Tissue microarrays were obtained from US Biomax for IHCs. The tissue microarray contains 160 NSCLC specimens and 32 non-tumor lung tissues. The 160 NSCLC samples consist of 80 squamous carcinoma tissues and 80 adenocarcinomas, whereas the 32 non-tumor lung tissues consist of 19 normal lung tissues and 13 cancer adjacent normal tissues. One tissue was unknown in sex, age, and TNM, and 15 tissues were unknown in grade. The tissue microarrays were determined using the UltraSensitive ${ }^{\mathrm{TM}}$ S-P (mouse/rabbit) IHC kit (Maxim, Fuzhou, China) according to the manufacturer's guidelines. The monoclonal antibodies $12 \mathrm{C} 7$ or $9 \mathrm{~B} 8$ were incubated at $10 \mu \mathrm{g} / \mathrm{ml}$. The expression levels of the proteins were scored by malignant/epithelial cells staining intensity and the percentage of immunoreactive cells. Tissues with no staining were rated as 0 , with faint staining or moderate to strong staining in $25 \%$ of the cells as 1 , with moderate staining or strong staining in $25-50 \%$ of the cells as 2 , and with strong staining in $50 \%$ of the cells as 3. Lung cancer tissues that registered levels 0 and 1 were defined as negative for expression, whereas samples at levels 2 or 3 were defined as positive.

Statistical analysis. Statistical analysis was performed with SPSS 13.0 software (Chicago, IL, USA). All numerical data were expressed as the average of the values obtained, and the standard deviation (SD) calculated. Data were analyzed using the two-tailed Student's t-test or $\lambda^{2}$ analysis unless otherwise specified. Data were considered significant at $\mathrm{p}<0.05$ and $\mathrm{p}<0.001$.

\section{Results}

Lung cancer stem-like cells are enriched in SPCA-1 and A549 cell lines via sphere-forming culture. We performed the sphereforming culture to enrich LCSCs. Both SPCA-1 and A549 cells could form non-adherent spheres when cultured in SFM. The sphere cells could be serially passaged and the third-generation spheres were used for all subsequent experiment. The self-renewal assay showed that the number of colonies formed by sphere cells was superior to those formed by parental cells in both SPCA-1 and A549 cell lines (Fig. 1A). Several studies demonstrated that LCSLCs might be responsible for cancer metastasis (27-29). Thus, we performed Matrigel Transwell assay to compare the invasive potentials of sphere cells with their parental cells. The results showed that more sphere cells passed through the Matrigel than their parental cells (Fig. 1B). RT-qPCR was employed to analyze the stem cell-related gene expression profiles of parental and sphere cells in both cell lines. Results indicated that the mRNA level of the stem cell markers Sox2, Nanog and Oct4 increased in the sphere cells (Fig. 1C). Then, we established a xenograft model to assess the tumorigenic capacity of the sphere cells from SPCA-1 and A549 cell lines as compared to their parental cells. As shown in Table II, the sphere cells possess much stronger tumorigenic potentials than their parental cells, since $1 \times 10^{4}$ sphere cells can 
A
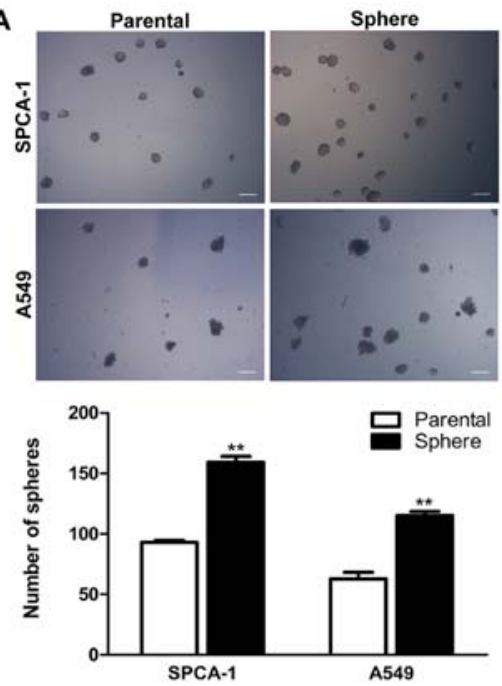

C

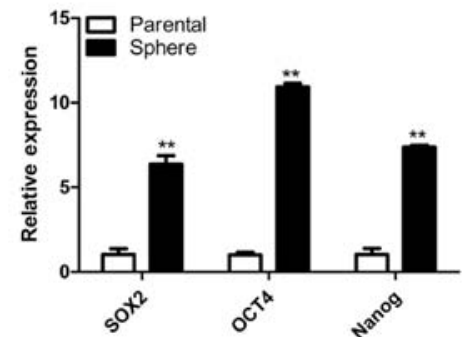

B
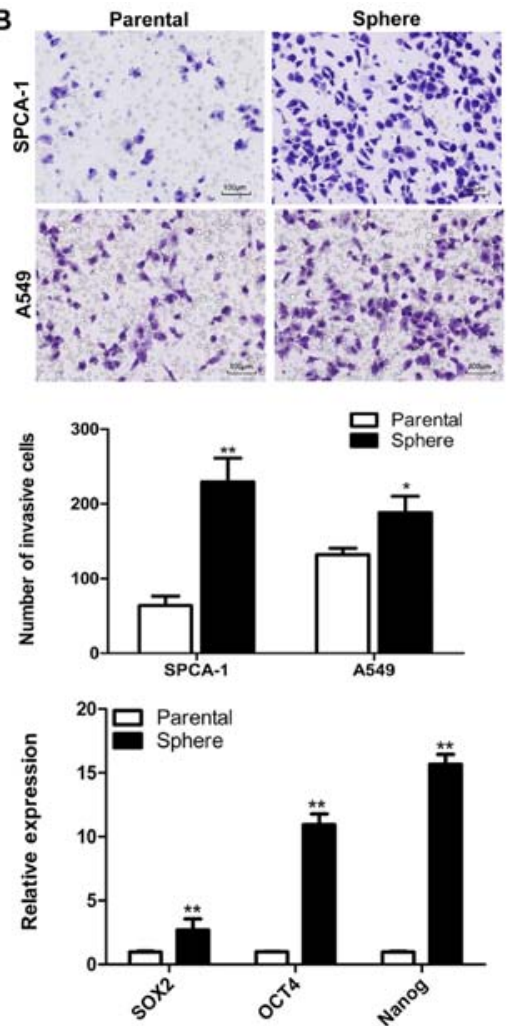

Figure 1. Sphere cells show increased LCSCs properties. (A) Analysis of sphere formation abilities in SPCA-1 and A549 parental and sphere cells. A representative image is shown in the upper panel. Statistical analysis for the triplicate is shown on the lower panel. Scale bar, $200 \mu \mathrm{m}$. (B) The Matrigel invasion assay. A representative image of the invaded cells is shown on the upper panel. Statistical analysis for the triplicate is shown on the lower panel. (C) mRNA expression of stem cell markers Sox2, Oct4, Nanog in SPCA-1 (left panel) and A549 (right panel) parental and sphere cells measured by RT-qPCR that was normalized with respect to $G A P D H$. All data were presented as mean \pm SD of at least three different experiments.

A

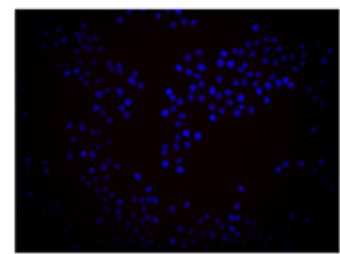

B
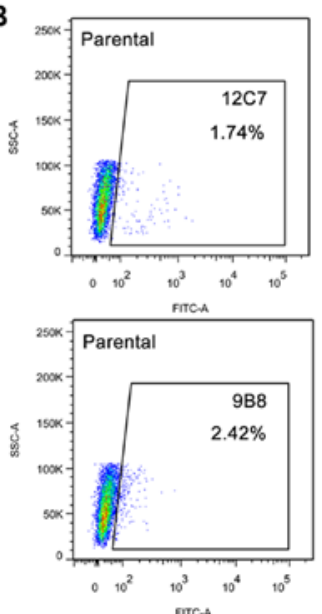
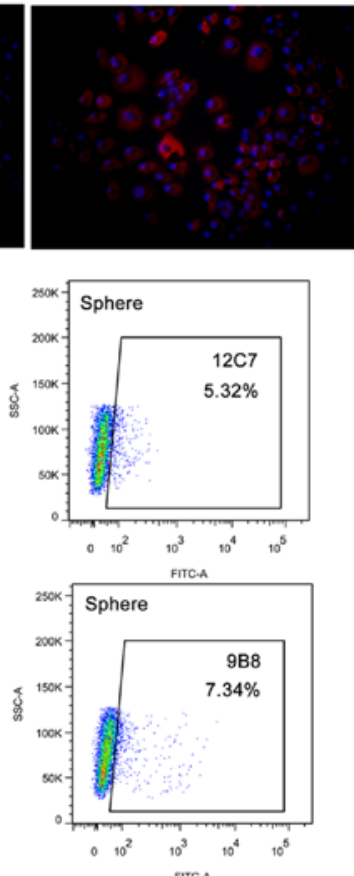
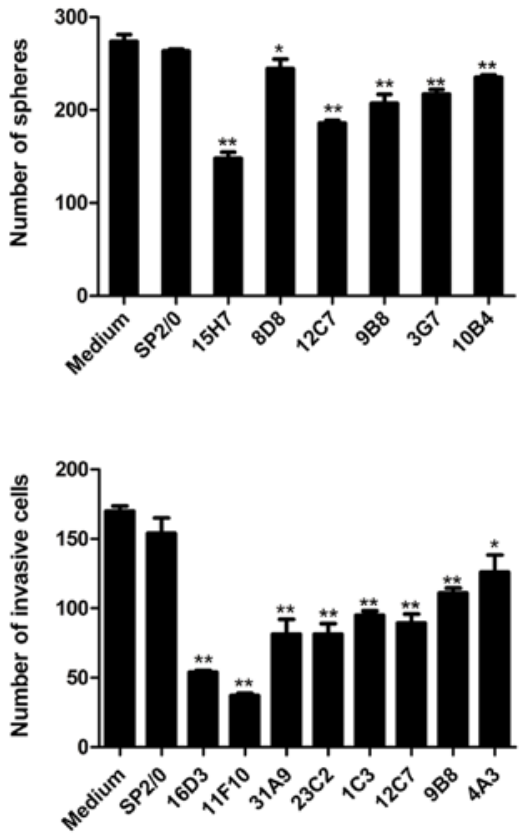

Figure 2. Screening for the functional mAbs that target LCSCs. (A) Fixed cell immunofluorescence was used for screening mAbs that could recognize lung cancer cell lines. A representative negative (left panel) and positive (right panel) image of SPCA-1 cells are shown. (B) FACS analysis for mAbs whose target antigens expressions can be enriched in sphere cells compared with the parental cells in SPCA-1 cells and A549 cells. The experiments were repeated three times. mAbs with $\geq 1.5$-fold enrichment, with a value of $\mathrm{p}<0.05$, were chosen for further screening. The images of $12 \mathrm{C} 7$ and $9 \mathrm{~B} 8$ in SPCA-1 cells are shown. (C) Sphere-forming inhibition assay and invasion inhibition assay were performed in SPCA-1 and A549 sphere cells. Six mAbs showed significant sphere inhibition ability on SPCA-1 sphere cells (upper panel) and 8 mAbs showed significant invasion inhibition ability on SPCA-1 sphere cells (lower panel). Data are the means $\pm \mathrm{SD}$ for three independent measurements. " $\mathrm{p}<0.05$ vs. SP $2 / 0$ group; ${ }^{* *} \mathrm{p}<0.01 \mathrm{vs.} \mathrm{SP} 2 / 0$ group. 

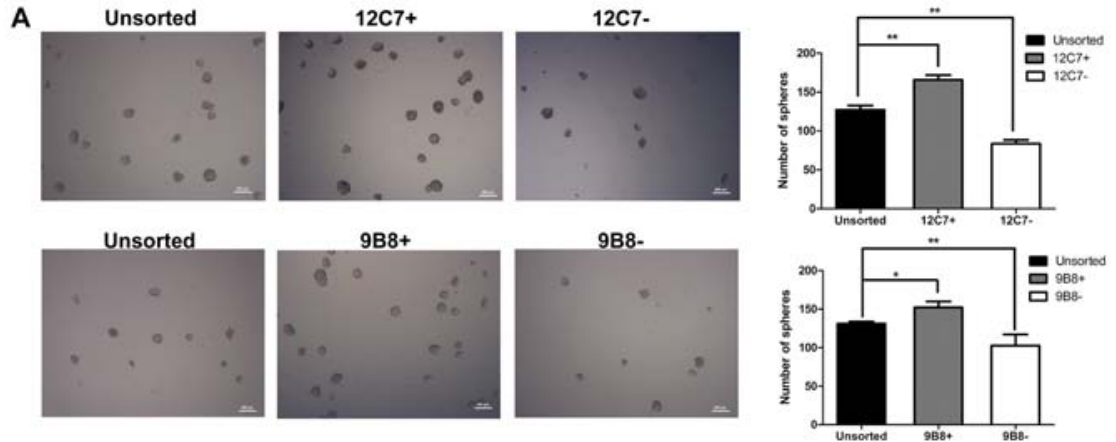

B

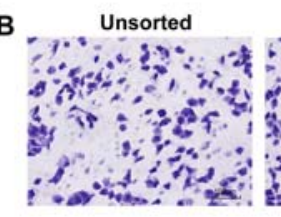

$12 \mathrm{C} 7+$
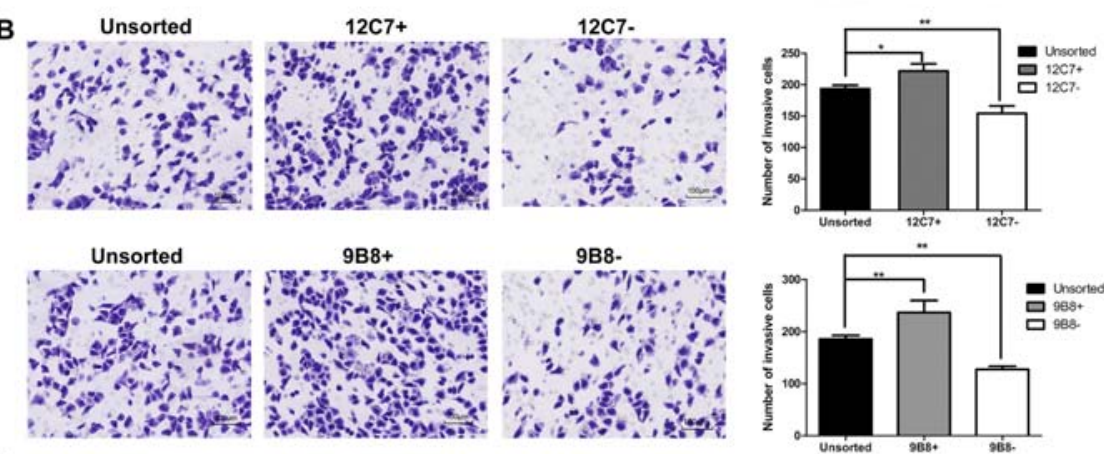

C
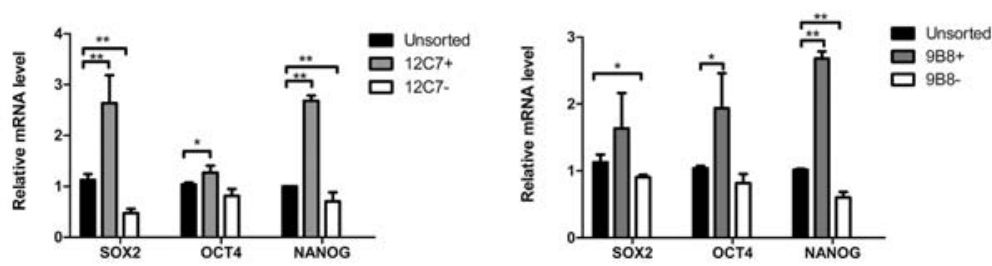

Figure 3. 12C7-positve cells and 9B8-positve cells have cancer stem cell properties. (A) Analysis of self-renewal abilities in the sphere-forming assay of 12C7-positive cells and 9B8-positive cells compared with their corresponding negative and unsorted cells. Scale bar, $200 \mu \mathrm{m}$. (B) Transwell invasion assay of 12C7-positive cells and 9B8-positive cells compared with their corresponding negative and unsorted cells. (C) mRNA expression of stem cell marker by RT-qPCR (normalized to GAPDH) in 12C7-positive cells and 9B8-positive cells compared with their corresponding negative and unsorted cells. Data are presented as mean \pm SD from three independent experiments.

Table II. Tumorigenicity assay of parental and sphere cells from SPCA-1 and A549 cell lines.

\begin{tabular}{lcccc}
\hline Cell type & $1 \times 10^{6}$ & $1 \times 10^{5}$ & $1 \times 10^{4}$ & $5 \times 10^{3}$ \\
\hline SPCA-1 parental & $5 / 5$ & $2 / 5$ & $0 / 5$ & $0 / 5$ \\
SPCA-1 sphere & $5 / 5$ & $5 / 5$ & $3 / 5$ & $1 / 5$ \\
A549 parental & $3 / 5$ & $0 / 5$ & $0 / 5$ & $0 / 5$ \\
A549 sphere & $5 / 5$ & $3 / 5$ & $1 / 5$ & $0 / 5$ \\
\hline
\end{tabular}

initiate tumor formation both in SPCA-1 and A549 cell lines while there were no nodules found in the parental cell group with the same cell number inoculated (Table II).

Screening of functional mAbs targeting LCSCs from multipotent antibody library. We constructed a multipotent CSC monoclonal antibody library that contained $2,976 \mathrm{mAbs}$ by immunizing $\mathrm{BLAB} / \mathrm{c}$ mice with T3A-A3 cells. The hybridoma supernatants were collected using standard methods, and $1,196 \mathrm{mAbs}$ were reserved with the antibody concentration assessed $>10 \mu \mathrm{g} / \mathrm{ml}$ by ELISA. From the $1,196 \mathrm{mAbs}$, a total of $66 \mathrm{mAbs}$ showed reactivity to both SPCA-1 and A549 cell lines by fixed cell immunofluorescence (Fig. 2A). Thus, we further screened the library aiming to identify the monoclonal antibodies that might bind specifically to LCSLCs and inhibit the self-renewal and invasion. Firstly, viable cell flow cytometry analysis assay was performed to detect the expression of antibody targeted antigens in parental and sphere cells of SPCA-1 and A549 cell lines. As a result, 33 mAbs targeted antigens could be enriched in sphere cells compared with the parental cells in both SPCA-1 and A549 cell line (Fig. 2B). Next, we screened the above $33 \mathrm{mAbs}$ for their sphereforming inhibition ability. Six mAbs showed significant inhibition ability on SPCA-1 and A549 sphere cells (Fig. 2C). Subsequently, the invasion inhibition assay revealed that 8 mAbs among $33 \mathrm{mAbs}$ can suppress the invasion of SPCA-1 and A549 sphere cells (Fig. 2C). Two mAbs, 12C7 and 9B8, showed both sphere-forming inhibition and invasion inhibition abilities. Therefore, the two mAbs were chosen to be studied further.

Isolation and characterization of 12C7-positive cells and 9B8-positive cells. To characterize the 12C7-positive cells and 9B8-positive cells, FACS sorting was performed in both SPCA-1 and A549 sphere cells. We evaluated the self-renewal potential, and the results showed that the number of spheroid colonies formed by positive cells was superior to those formed by negative cells and unsorted cells (Fig. 3A). Then, we 
A

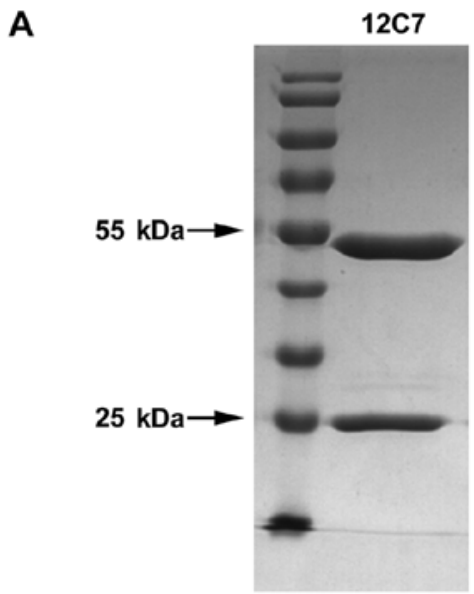

C

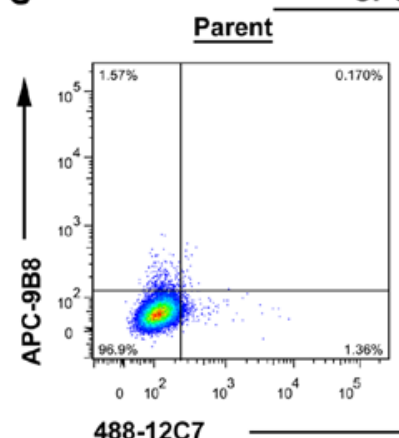

9B8

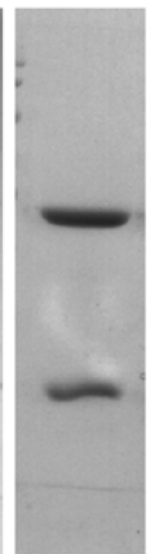

PCA-1

B

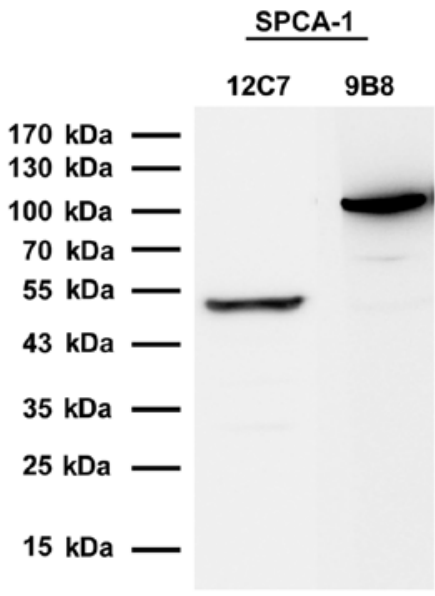

A549

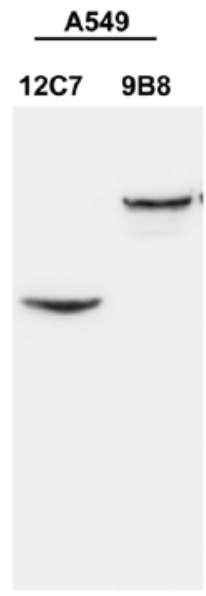

Spheres

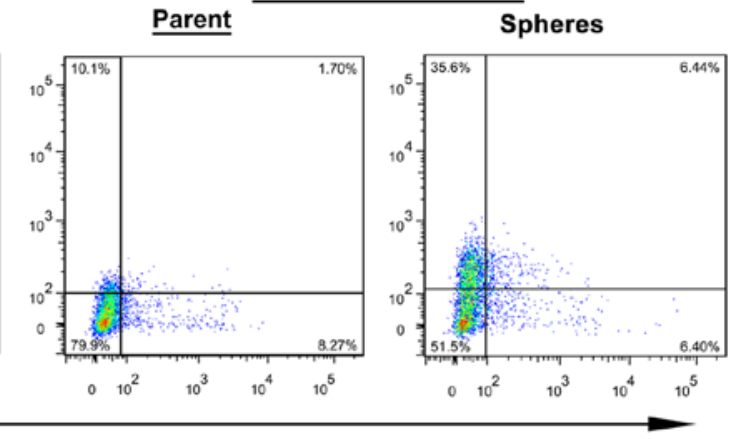

Figure 4. mAbs $12 \mathrm{C} 7$ and 9B8 were purified, and they recognized the rare percentage of the same cells. (A) mAbs $12 \mathrm{C} 7$ and $9 \mathrm{~B} 8$ were purified at $>90 \%$ purity. (B) Identification of mAbs 12C7 and 9B8 target antigens by western blot analysis. (C) FACS plot of mAbs $12 \mathrm{C} 7$ and 9B8 recognized cells. All experiments were repeated in triplicate.

investigated whether the positive cells possess higher invasion capacity. As shown in the results, the positive cells were considerably more invasive than the negative and unsorted cells (Fig. 3B). We further explored the expression of several 'stemness'-associated genes, including Sox2, Nanog and Oct4. RT-qPCR showed that both 12C7-positive and 9B8-positive cells expressed higher mRNA levels of stemness-related markers than the negative and unsorted cells (Fig. 3C).

MAb $12 C 7$ and $9 B 8$ identified two distinct subpopulations of LCSCs. The isotypes of antibody $12 \mathrm{C} 7$ and 9B8 were both IgG1 (data not shown) determined by commercial isotyping kit. The two antibodies were purified by protein $\mathrm{G}$ column and the purity achieved was $>90 \%$ (Fig. 4A). We extracted proteins from the lung cancer cell lines SPCA-1 and A549 for western blot analysis. The molecular weight of antigen is $47 \mathrm{kDa}$ recognized by $12 \mathrm{C} 7$ and $100 \mathrm{kDa}$ by $9 \mathrm{~B} 8$ (Fig. 4B). The overlap of $12 \mathrm{C}^{+}$cells with $9 \mathrm{~B} 8^{+}$cells was estimated by flow cytometry. mAb 12C7 and 9B8 double-positive cells were only detected in extremely rare cells which comprised $0.17 \%$ of the total cells in SPCA-1 parent cells and $0.65 \%$ in spheres (Fig. 4C). Furthermore, the rare percentage of double-positive cells was also determined in A549 parent and sphere cells. The results demonstrated that $\mathrm{mAb} 12 \mathrm{C} 7$ and 9B8 might identify two distinct subpopulations of LCSCs (Fig. 4C).

Effects of mAbs $12 C 7$ and $9 B 8$ on the LCSLCs in vitro and in vivo. To investigate the effect of the antibody on self-renewal and invasion capacity in vitro, we incubated A549 and SPCA-1 sphere cells with three different concentrations of mAbs $12 \mathrm{C} 7$ and $9 \mathrm{~B} 8$ for $2 \mathrm{~h}$ at $37^{\circ} \mathrm{C}$, following which, the sphere-forming assay and Transwell invasion assay were performed as previously described. For the sphere forming assay, the same concentration of fresh mAbs was added every two days. The results showed that $\mathrm{mAbs} 12 \mathrm{C} 7$ and 9B8 can both suppress the self-renewal and invasion of sphere cells in a dose-dependent manner (Fig. 5A and B). Then nude mice bearing SPCA-1 sphere cell xenografts were treated by $12 \mathrm{C} 7$ or $9 \mathrm{~B} 8 \mathrm{mAbs}$. The mean tumor volumes after treatment with mAb $12 \mathrm{C} 7$ or $9 \mathrm{~B} 8$ reduced in a dose-dependent manner. For $\mathrm{mAb} 12 \mathrm{C} 7$, the tumor weight inhibition rates for high $(40 \mathrm{mg} / \mathrm{kg})$, moderate $(10 \mathrm{mg} / \mathrm{kg})$, and low $(0.25 \mathrm{mg} / \mathrm{kg})$ dose were $45.27,30.89$ and $21.42 \%$, respectively, whereas for $\mathrm{mAb} 9 \mathrm{~B} 8$, the tumor weight inhibition rates were $35.2,27.71$ and $18.77 \%$, respectively (Fig. 5C and D). These results indicated that both $12 \mathrm{C} 7$ and 9B8 are functional mAbs, which might be used as potential therapeutic antibodies for lung cancer treatment.

Combination effects of mAbs $12 C 7$ and $9 B 8$ on the LCSLCs in vitro and in vivo. As mAb $12 \mathrm{C} 7$ and $9 \mathrm{~B} 8$ might identify two distinct subpopulations of LCSLCs, we explored the combination effects of mAbs 12C7 and 9B8 on the LCSLCs in vitro and in vivo. It was found that the group of combination antibodies had a notably improved effect on suppressing the self-renewal (Fig. 5A) and invasion (Fig. 5B) of LCSLCs than the group of individual antibodies in vitro. Interestingly, in the in vivo 
A

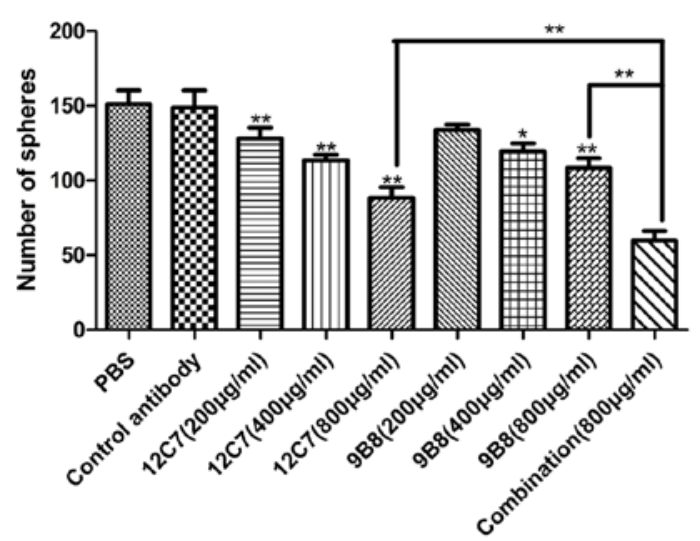

C

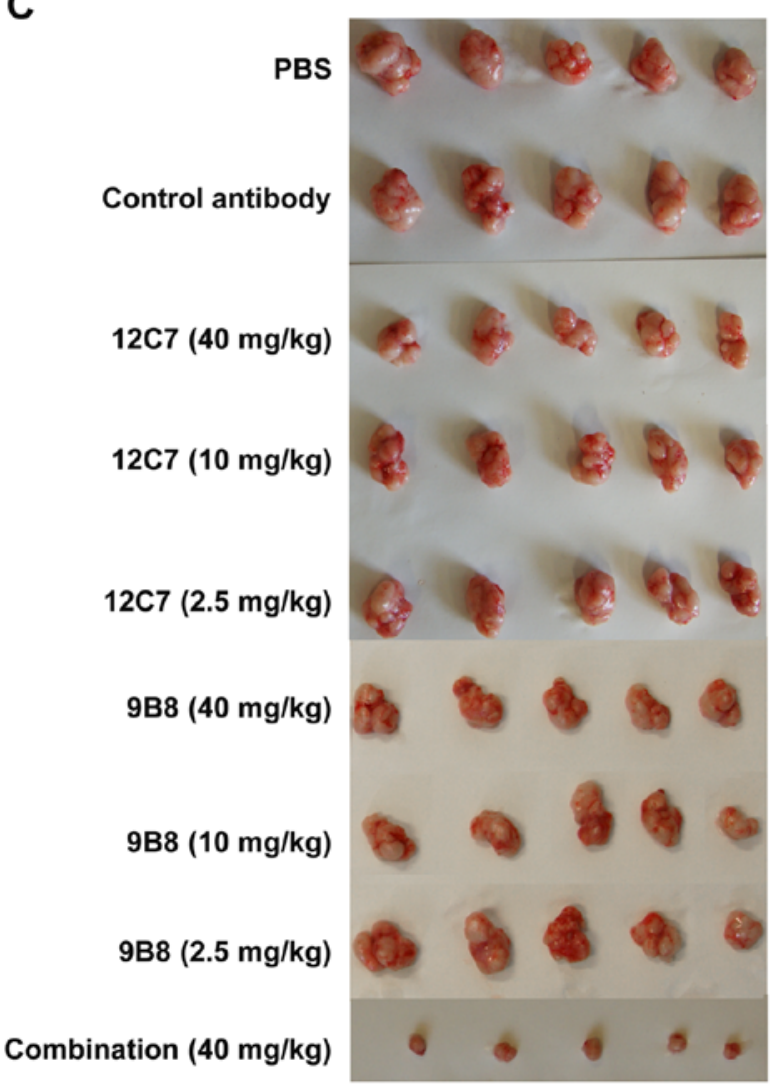

B
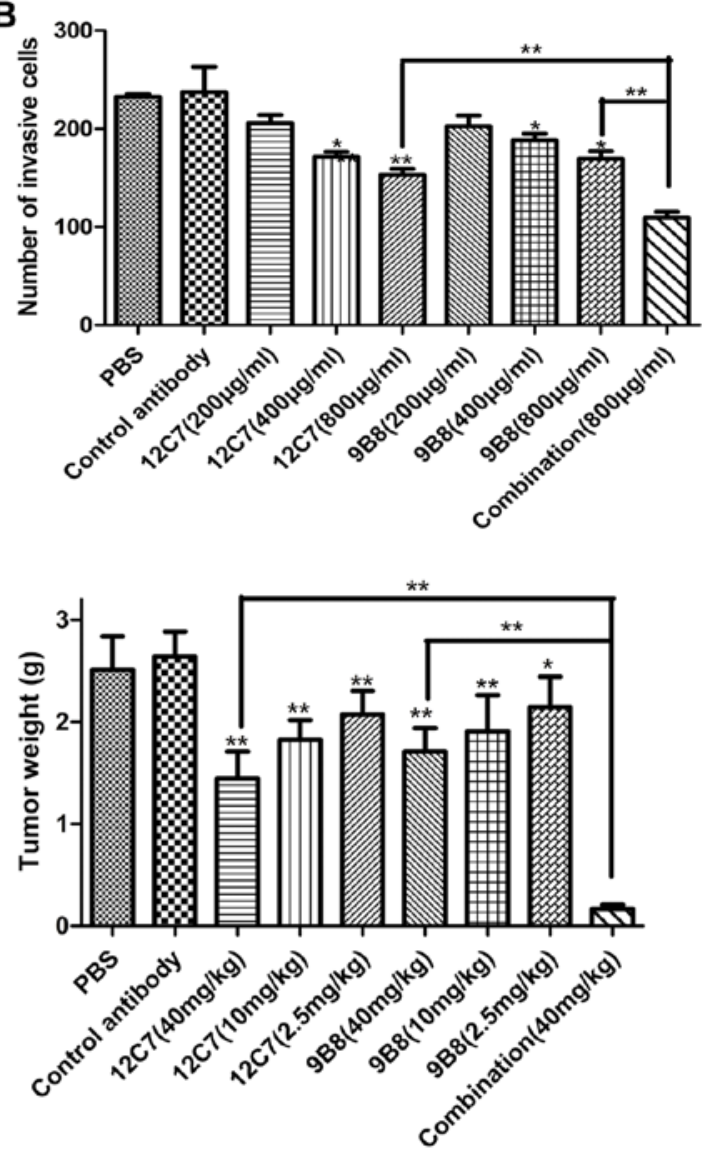

D

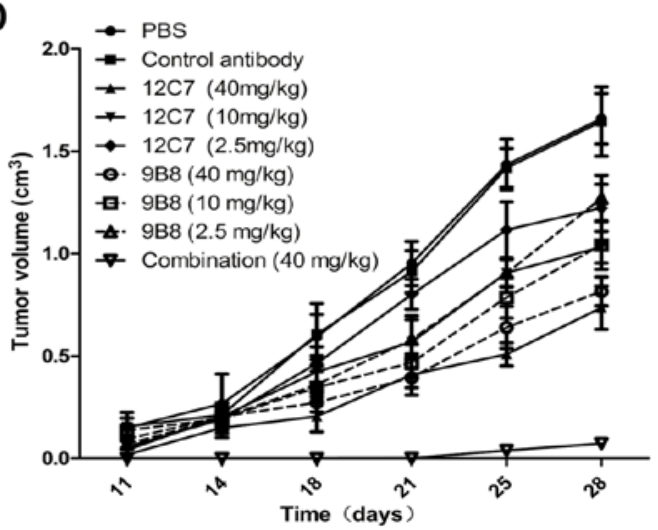

Figure 5. The effects of $\mathrm{mAb} 12 \mathrm{C} 7$ and 9B8 in vitro and in vivo. (A) The self-renewal of SPCA-1 sphere cells was inhibited by mAb 12C7 and 9B8 in a dosedependent manner. "p $<0.05$ or ${ }^{* *} \mathrm{p}<0.01$ of the individual antibody group compared with the control antibody group. (B) MAb 12C7 and 9B8 suppress the Transwell invasion of SPCA-1 sphere cells. " $\mathrm{p}<0.05$ or ${ }^{* *} \mathrm{p}<0.01$ of the individual antibody group compared with the control antibody group. (C) The effect of $\mathrm{mAb} 12 \mathrm{C} 7$ and 9B8 treatment on the SPCA-1 sphere cells xenografts tumor growth. "p $<0.05$ or ${ }^{* *} \mathrm{p}<0.01$ of the individual antibody group compared with the control antibody group. (D) Growth curve of xenograft tumor treated with different doses of mAb 12C7 and 9B8.

experiment, the combination group inhibited the tumor growth at the highest rate of $93 \%$, which is significantly superior to the same concentration group of the individual antibody (Fig. 5C and D). This result strongly suggested that the combination antibody treatment may be used as a potential novel method for lung cancer therapy.

Clinical significance of antigens recognized by $m A b 12 C 7$ and $9 B 8$ for NSCLC. The antigen expression levels of $\mathrm{mAb} 12 \mathrm{C} 7$ and 9B8 in human lung cancer tissue were determined by IHC in a tissue microarray. The results showed that the antigen recognized by $\mathrm{mAb} 12 \mathrm{C} 7$ account for a high proportion in $135(84.4 \%)$ lung cancer tissues and a low proportion of 7 (21.9\%) non-tumor lung tissues (Table III). Moreover, the antigen recognized by mAb 9B8 was highly expressed in $132 / 160(82.5 \%)$ lung cancer tissues and lowly expressed in $8 / 32$ (25\%) normal lung tissues (Table III). Furthermore, the correlations between mAbs targeted antigens expression and clinicopathological parameters were evaluated. The results demonstrated that there was a significant correlation between the expression of the $\mathrm{mAb} 12 \mathrm{C} 7$ targeted protein and the pathological grade, indicating a high level of expression in higher-grade tumors (Table IV). Moreover, the positive expression of $\mathrm{mAb} 9 \mathrm{~B} 8$ targeted protein was significantly 
Table III. Upregulation of mAb $12 \mathrm{C} 7$ or mAb 9B8 targeted protein in NSCLC specimens compared to non-cancerous lung specimens.

\begin{tabular}{|c|c|c|c|c|c|c|c|}
\hline \multirow[b]{2}{*}{ Group } & \multirow[b]{2}{*}{ Cases (n) } & \multicolumn{3}{|c|}{$12 \mathrm{C} 7$} & \multicolumn{3}{|c|}{$9 \mathrm{~B} 8$} \\
\hline & & Positive (\%) & Negative (\%) & P-value & Positive (\%) & Negative (\%) & P-value \\
\hline NSCLC & 160 & 84.4 & 15.6 & $<0.01$ & 82.5 & 17.5 & $<0.01$ \\
\hline Non-tumor & 32 & 21.9 & 78.1 & & 25 & 75 & \\
\hline
\end{tabular}

Table IV. Correlation between clinicopathological characteristics with mAb 12C7 or 9B8 targeted proteins.

\begin{tabular}{|c|c|c|c|c|c|c|c|}
\hline \multirow[b]{2}{*}{ Characteristics } & \multirow[b]{2}{*}{$\begin{array}{c}\text { Cases } \\
\text { (n) }\end{array}$} & \multicolumn{3}{|c|}{$12 \mathrm{C} 7$} & \multicolumn{3}{|c|}{ 9B8 } \\
\hline & & $\begin{array}{c}\text { Positive } \\
\mathrm{N}(\%)\end{array}$ & $\lambda^{2}$ & P-value & $\begin{array}{l}\text { Positive } \\
\mathrm{N}(\%)\end{array}$ & $\lambda^{2}$ & P-value \\
\hline Age & & & 0.002 & 0.968 & & 1.098 & 0.295 \\
\hline$<50$ & 44 & $37(84.0)$ & & & $34(77.3)$ & & \\
\hline$\geq 50$ & 115 & $97(84.3)$ & & & $97(84.3)$ & & \\
\hline Gender & & & 0.139 & 0.709 & & 0.04 & 0.841 \\
\hline Male & 116 & $97(83.6)$ & & & $96(82.8)$ & & \\
\hline Female & 43 & $37(86.0)$ & & & $35(81.4)$ & & \\
\hline Pathology & & & 0.427 & 0.514 & & 6.234 & 0.013 \\
\hline Sequamous & 80 & $66(82.5)$ & & & $60(75)$ & & \\
\hline Adenocarcinoma & 80 & $69(86.25)$ & & & $72((90)$ & & \\
\hline Grade & & & 13.22 & 0.001 & & 4.92 & 0.085 \\
\hline 1 & 22 & $14(63.6)$ & & & $22(100)$ & & \\
\hline 2 & 82 & $73(83.0)$ & & & $67(81.7)$ & & \\
\hline 3 & 41 & $39(95.1)$ & & & $33(80.5)$ & & \\
\hline Depth of invasion & & & 0.679 & 0.712 & & 2.87 & 0.239 \\
\hline $\mathrm{TX}+\mathrm{T} 1$ & 22 & $19(86.4)$ & & & $18(81.8)$ & & \\
\hline $\mathrm{T} 2$ & 108 & $92(85.2)$ & & & $86(76.9)$ & & \\
\hline $\mathrm{T} 3+\mathrm{T} 4$ & 29 & $23(79.3)$ & & & $27(93.1)$ & & \\
\hline $\begin{array}{l}\text { Lymph node } \\
\text { involvement }\end{array}$ & & & 0.064 & 0.801 & & 8.29 & 0.004 \\
\hline No & 80 & $68(85.0)$ & & & $59(73.8)$ & & \\
\hline N1 & 79 & $66(83.5)$ & & & $72(91.1)$ & & \\
\hline Metastasis & & & 0.378 & 0.539 & & 0.43 & 0.511 \\
\hline M0 & 157 & $132(84.1)$ & & & $129(82.2)$ & & \\
\hline M1 & 2 & $2(100)$ & & & $2(100)$ & & \\
\hline
\end{tabular}

associated with the tumor pathology, which indicated that the positive expression of $\mathrm{mAb} 9 \mathrm{~B} 8$ readily occurred in adenocarcinoma. The positive expression of mAb 9B8 targeted protein was also significantly associated with lymph node involvement.

\section{Discussion}

In this study, we identified two mAbs, $12 \mathrm{C} 7$ and $9 \mathrm{~B} 8$, that can specifically bind to the LCSLCs and inhibit the biological characteristics involving self-renewal and invasiveness. Interestingly, we also found that these two antibodies separately targeted the two distinct LCSLCs, and the combination therapeutic effect was significantly superior to the independent effects both in vitro and in vivo.

Monoclonal antibody-based cancer therapy is considered to be more efficient and less toxic than the conventional therapy. In the last two decades, the mAbs drug is becoming a vital therapeutic alternative for certain common types of cancers, including lymphoma, breast, colon, and lung 
cancers. The CSC model suggests that tumors are composed of a heterogeneous group of cells, out of which a small subset of cells, called CSCs, could be responsible for the tumor initiation and recurrence. Due to the functional relevance, CSCs can be natural candidates for a targeted therapy with mAbs. For example, anti-ABCG2 mAbs that target CD138 CD34- MM cancer stem-like cells in combination with PTX iron oxide NPs (PTX-NPs), can significantly suppress the proliferation and invasion of $\mathrm{MM}$ cancer cells both in vitro and in vivo (22).

Multiple subpopulations of LCSLCs have been reported in lung cancer tissues, such as SP (30), CD133 (16), CD44 (31), and ALDH (32). However, these markers also express on normal stem cells, and they are mostly uncorrelated with the stem cell functions. To identify the novel potential therapeutic antibodies targeting LCSLCs, in this study, we present a screening approach involving the isolation and selection of mAbs for their ability to inhibit LCSLCs self-renewal and invasion. We have constructed a large capacity hybridoma monoclonal antibody library containing 2976 monoclonals from BLAB/c mice immunized with a multipotent CSC cell line T3A-A3. This resulted in the isolation of $66 \mathrm{mAbs}$ that could react with lung cancer cells. Through FACs and function inhibition assay, we obtained $2 \mathrm{mAbs}, 12 \mathrm{C} 7$ and 9B8. The stem cell properties of 12C7 positive cells and 9B8 positive cells were validated by functional experiments and higher stem-cell related gene expression. Furthermore, they could inhibit self-renewal and invasion of LCSCs in a dose-dependent manner.

We further analyzed the relationship of the two mAbs target cells. Western blot analysis confirmed that both the mAbs recognized different weights of antigens, and FACs proved that these two antibodies recognized rare double-positive cells. Thus, it can be concluded that these two antibodies identified two distinctive subpopulations of LCSCs. According to the CSC hypothesis, theoretically, tumors can be cured as long as CSCs are eliminated completely. Moreover, it has been found that the treatment effect for a particular subpopulation of CSCs is extremely limited in the study of cancer stem cells. Herein, we found that the combination therapeutic effect of these two mAbs was significantly superior to the individual effects both in vitro and in vivo. Moreover, both $12 \mathrm{C} 7$ targeted antigen and 9B8 targeted antigen were highly expressed in tumor tissues according to our IHC results in tissue microarray assays, which can ensure the curative effect once the antibodies were applied in clinical practice. Our results suggested that the application of the combination therapy against different subpopulations of cancer stem cells may significantly improve the prognosis of lung cancer.

Despite the remarkable development of mAb treatment, the need for novel therapeutic antibodies persists. The key challenge is the identification of novel targets that are suitable for therapeutic antibodies. Here, we report a screening approach for functional antibodies that target LCSCs from the constructed multipotent antibody library. However, we should perform a spectrometric analysis of LC-MS/MS to identify the targets of the selected antibodies and investigate the underlying mechanism in the future.

In conclusion, we successfully identified two functional antibodies that specifically target LCSCs. They can inhibit cancer self-renewal and invasion both in vitro and in vivo.
Furthermore, we confirmed that these two antibodies represent two distinct subpopulations of LCSCs, and a combination of them can significantly improve the therapeutic efficiency, implying a novel therapeutic approach for clinical strategy.

\section{Acknowledgements}

The present study was supported by the National Natural Science Foundation of China (grant no. 81172033), and National High-tech R\&D Program of China for Young Scholars (grant no. 2014AA020537).

\section{References}

1. Siegel RL, Miller KD and Jemal A: Cancer statistics, 2015. CA Cancer J Clin 65: 5-29, 2015.

2. Ferlay J, Soerjomataram I, Dikshit R, Eser S, Mathers C, Rebelo M, Parkin DM, Forman D and Bray F: Cancer incidence and mortality worldwide: Sources, methods and major patterns in GLOBOCAN 2012. Int J Cancer 136: E359-E386, 2015.

3. Charafe-Jauffret E, Ginestier C, Iovino F, Wicinski J, Cervera N, Finetti P, Hur MH, Diebel ME, Monville F, Dutcher J, et al: Breast cancer cell lines contain functional cancer stem cells with metastatic capacity and a distinct molecular signature. Cancer Res 69: 1302-1313, 2009.

4. Lapidot T, Sirard C, Vormoor J, Murdoch B, Hoang T, CaceresCortes J, Minden M, Paterson B, Caligiuri MA and Dick JE: A cell initiating human acute myeloid leukaemia after transplantation into SCID mice. Nature 367: 645-648, 1994.

5. Ricci-Vitiani L, Lombardi DG, Pilozzi E, Biffoni M, Todaro M, Peschle $\mathrm{C}$ and De Maria R: Identification and expansion of human colon-cancer-initiating cells. Nature 445: 111-115, 2007.

6. Yang ZF, Ho DW, Ng MN, Lau CK, Yu WC, Ngai P, Chu PW, Lam CT, Poon RT and Fan ST: Significance of CD90 ${ }^{+}$cancer stem cells in human liver cancer. Cancer Cell 13: 153-166, 2008.

7. Vermeulen L, Sprick MR, Kemper K, Stassi G and Medema JP: Cancer stem cells - old concepts, new insights. Cell Death Differ 15: 947-958, 2008.

8. Beck B and Blanpain C: Unravelling cancer stem cell potential. Nat Rev Cancer 13: 727-738, 2013.

9. Medema JP: Cancer stem cells: The challenges ahead. Nat Cell Biol 15: 338-344, 2013.

10. Takebe N, Harris PJ, Warren RQ and Ivy SP: Targeting cancer stem cells by inhibiting Wnt, Notch, and Hedgehog pathways. Nat Rev Clin Oncol 8: 97-106, 2011.

11. Hoey T, Yen WC, Axelrod F, Basi J, Donigian L, Dylla S, Fitch-Bruhns M, Lazetic S, Park IK, Sato A, et al: DLL4 blockade inhibits tumor growth and reduces tumor-initiating cell frequency. Cell Stem Cell 5: 168-177, 2009.

12. Okamoto OK and Perez JF: Targeting cancer stem cells with monoclonal antibodies: A new perspective in cancer therapy and diagnosis. Expert Rev Mol Diagn 8: 387-393, 2008.

13. Sharma BK, Manglik V, O'Connell M, Weeraratna A, McCarron EC, Broussard JN, Divito KA, SimbulanRosenthal CM, Rosenthal DS and Zapas JL: Clonal dominance of $\mathrm{CD}_{133^{+}}$subset population as risk factor in tumor progression and disease recurrence of human cutaneous melanoma. Int $\mathbf{J}$ Oncol 41: 1570-1576, 2012.

14. Wright $\mathrm{MH}$, Calcagno AM, Salcido CD, Carlson MD, Ambudkar SV and Varticovski L: Brcal breast tumors contain distinct $\mathrm{CD} 44^{+} / \mathrm{CD} 24^{-}$and $\mathrm{CD} 133^{+}$cells with cancer stem cell characteristics. Breast Cancer Res 10: R10, 2008

15. Hermann PC, Huber SL, Herrler T, Aicher A, Ellwart JW, Guba M, Bruns CJ and Heeschen C: Distinct populations of cancer stem cells determine tumor growth and metastatic activity in human pancreatic cancer. Cell Stem Cell 1: 313-323, 2007.

16. Eramo A, Lotti F, Sette G, Pilozzi E, Biffoni M, Di Virgilio A, Conticello C, Ruco L, Peschle C and De Maria R: Identification and expansion of the tumorigenic lung cancer stem cell population. Cell Death Differ 15: 504-514, 2008.

17. Scott AM, Allison JP and Wolchok JD: Monoclonal antibodies in cancer therapy. Cancer Immun 12: 14, 2012.

18. Coulson A, Levy A and Gossell-Williams M: Monoclonal antibodies in cancer therapy: Mechanisms, successes and limitations. West Indian Med J 63: 650-654, 2014. 
19. Davis TA, Grillo-López AJ, White CA, McLaughlin P, Czuczman MS, Link BK, Maloney DG, Weaver RL, Rosenberg J and Levy R: Rituximab anti-CD20 monoclonal antibody therapy in non-Hodgkin's lymphoma: Safety and efficacy of re-treatment. J Clin Oncol 18: 3135-3143, 2000.

20. Köhler G and Milstein C: Continuous cultures of fused cells secreting antibody of predefined specificity. Nature 256: 495-497, 1975.

21. Boyiadzis M and Foon KA: Approved monoclonal antibodies for cancer therapy. Expert Opin Biol Ther 8: 1151-1158, 2008.

22. Yang C, Xiong F, Wang J, Dou J, Chen J, Chen D, Zhang Y, Luo $S$ and Gu N: Anti-ABCG2 monoclonal antibody in combination with paclitaxel nanoparticles against cancer stem-like cell activity in multiple myeloma. Nanomedicine (Lond) 9: 45-60, 2014.

23. Morris MJ, Eisenberger MA, Pili R, Denmeade SR, Rathkopf D, Slovin SF, Farrelly J, Chudow JJ, Vincent M, Scher HI, et al: A phase I/IIA study of AGS-PSCA for castration-resistant prostate cancer. Ann Oncol 23: 2714-2719, 2012.

24. Sharkey RM, Hajjar G, Yeldell D, Brenner A, Burton J, Rubin A and Goldenberg DM: A phase I trial combining high-dose 90Y-labeled humanized anti-CEA monoclonal antibody with doxorubicin and peripheral blood stem cell rescue in advanced medullary thyroid cancer. J Nucl Med 46: 620-633, 2005.

25. Liu H, Zhang W, Jia Y, Yu Q, Grau GE, Peng L, Ran Y, Yang Z, Deng $\mathrm{H}$ and Lou J: Single-cell clones of liver cancer stem cells have the potential of differentiating into different types of tumor cells. Cell Death Dis 4: e857, 2013.
26. Sun L, Chen L, Sun L, Pan J, Yu L, Han L, Yang Z, Luo Y and Ran Y: Functional screen for secreted proteins by monoclonal antibody library and identification of Mac-2 Binding protein (Mac-2BP) as a potential therapeutic target and biomarker for lung cancer. Mol Cell Proteomics 12: 395-406, 2013.

27. Mani SA, Guo W, Liao MJ, Eaton EN, Ayyanan A, Zhou AY, Brooks M, Reinhard F, Zhang CC, Shipitsin M, et al: The epithelial-mesenchymal transition generates cells with properties of stem cells. Cell 133: 704-715, 2008.

28. Pang R, Law WL, Chu AC, Poon JT, Lam CS, Chow AK, Ng L, Cheung LW, Lan XR, Lan HY, et al: A subpopulation of CD26 cancer stem cells with metastatic capacity in human colorectal cancer. Cell Stem Cell 6: 603-615, 2010.

29. Fan F, Samuel S, Evans KW, Lu J, Xia L, Zhou Y, Sceusi E, Tozzi F, Ye XC, Mani SA, et al: Overexpression of snail induces epithelial-mesenchymal transition and a cancer stem cell-like phenotype in human colorectal cancer cells. Cancer Med 1: 5-16, 2012.

30. Ho MM, Ng AV, Lam S and Hung JY: Side population in human lung cancer cell lines and tumors is enriched with stem-like cancer cells. Cancer Res 67: 4827-4833, 2007.

31. Leung EL, Fiscus RR, Tung JW, Tin VP, Cheng LC, Sihoe AD, Fink LM, Ma Y and Wong MP: Non-small cell lung cancer cells expressing CD44 are enriched for stem cell-like properties. PLoS One 5: e14062, 2010

32. Liang D and Shi Y: Aldehyde dehydrogenase-1 is a specific marker for stem cells in human lung adenocarcinoma. Med Oncol 29: 633-639, 2012. 